Instituto Cubano de Investigación Cultural Juan Marinello,

Havana, Cuba

yeibetty@gmail.com

Yeisa Sarduy Herrera'

\title{
“O PROBLEMA RACIAL SE RESOLVERÁ QUANDO SE DESTRUÍREM A NEGRURA DO NEGRO E A BRANCURA DO BRANCO." ENTREVISTA COM O ANTROPÓLOGO PABLO RODRÍGUEZ RUIZ
}

Graduado em filosofia e mestre em antropologia sociocultural, Pablo Rodríguez Ruiz é pesquisador associado do Instituto Cubano de Antropologia (Ican), onde exerce o cargo de chefe do Departamento de Antropologia Sociocultural e coordena projeto sobre marginalidade e pobreza no contexto cubano da década de I990. No projeto nacional de ciência e técnica sobre etnicidade e relações raciais, foi o responsável pela pesquisa relacionada às determinações socioestruturais da questão racial em Cuba. Atualmente é chefe do projeto "Culturas do trabalho nas novas formas econômicas de atualização do modelo cubano". Entre suas publicações se encontram Los Nhanecas-Humbi de Angola: procesos etnosociales (Havana: Editorial de Ciencias Sociales, I992; Prêmio Pinos Nuevos); Las relaciones raciales en Cuba: estudios contemporáneos (Havana: Fundação Fernando Ortiz, 2012; Prêmio Academia de Ciências de Cuba); e Los marginales de las Alturas del Mirador: un estudio de caso (Havana: Fundação Fernando Ortiz, 20I 2; Prêmio Academia de Ciências de Cuba).

Esta entrevista vem aproximar o leitor do ambiente intelectual cubano contemporâneo. Como indica o título, nela ressalta-se o tema das relações raciais. Ao abarcar o conjunto das questões socioculturais e político-ideológicas suscitadas pela escravização de populações africanas nas Américas entre os séculos XVII e XIX, o tema abre um amplo espectro comparativo, retomando questões já sinalizadas em Sociologia \& Antropologia pela análise das contribuições precursoras do intelectual cubano Fernando Ortiz acerca de uma "história atlântica" (ver, a respeito, Myers, 20I5). 
No Brasil, como sabido, o estudo das relações raciais é inerente à própria formação das ciências sociais brasileiras. O problema da incorporação da população negra anteriormente escravizada na formação de uma nação brasileira é objeto de interesse e debate desde o clássico 0 animismo fetichista dos negros baianos, de Nina Rodrigues (2006), publicado em sua íntegra na França em I 900 e no Brasil em uma série de artigos divulgados em I896 e I897 na Revista Brazileira. Os anos 1930 trouxeram tanto a realização da pesquisa de campo aprofundada de Donald Pierson na Bahia (I97I) ${ }^{\mathrm{I}}$ como a publicação do clássico ensaístico Casa-grande \& senzala (1936), de Gilberto Freyre (I977). Nos anos I950, há inúmeras iniciativas que vão desde a coleta de escritos de diversos autores reunidos por Edison Carneiro (2005), na Antologia do negro brasileiro, como os artigos de Guerreiro Ramos (I954) e, em especial, o conjunto das pesquisas realizadas sob a égide do Projeto Unesco de relações raciais, coordenado por Alfred Métraux. Esse projeto reuniu uma plêiade de intelectuais que, ao pesquisar situações e cidades em diferentes regiões brasileiras, desvendaram não apenas o preconceito e a discriminação racial existentes no país, como estabeleceram distintos paradigmas conceituais e metodológicos para seu estudo que se desdobram até nossos dias (Maio, I999). Vale mencionar, entre outros, não só Florestan Fernandes e Roger Bastide (I959), que reuniram parte das pesquisas realizadas em São Paulo em Relações entre negros e brancos em São Paulo (I959), como Luiz da Costa Pinto (I998) e Oracy Nogueira (I985, I 998 [I952], 2007 e 2008 a e b). Este último autor, como se sabe, cunhou os conceitos de preconceito de origem e preconceito de marca (que elegem a ascendência e a cor da pele ou a aparência, respectivamente, como critério discriminatório) para distinguir o racismo tal como vigente nos Estados Unidos e no Brasil (ver, a respeito, Cavalcanti, I 996). ${ }^{2} \mathrm{O}$ racismo era por ele apreendido como um aspecto integrante de sistemas classificatórios mais amplos relacionados às características históricas e socioculturais da formação de cada uma dessas sociedades. Impossível não observarmos as semelhanças existentes entre a dinâmica do preconceito de marca, característico das relações raciais brasileiras, tal como a compreendeu Nogueira, e a relevância da cor da pele na dinâmica das representações sociais sobre a "raça" entendida como uma construção social, tal como observada por Herrera. Nesse sentido, é oportuna a publicação, também neste número de Sociologia \& Antropologia, de "Clara dos Anjos e as cores de Lima", artigo em que Lilia Moritz Schwarcz estuda o uso feito pelo escritor Lima Barreto dos matizes e tonalidades das cores sociais, que, no Brasil, operam como marcadores sociais de diferença.

A entrevista de Pablo Rodríguez Ruiz, conduzida por Yeisa Sarduy Herrera, convida assim de modo proveitoso a um renovado diálogo. 
Yeisa Sarduy Herrera. Agradeço sua disposição para conceder a entrevista e começo nossa conversa com uma pergunta que se impõe: como o senhor define a categoria raça?

Pablo Rodríguez Ruiz. A raça é uma construção social. A esse respeito há um acordo entre todos os antropólogos e, eu acredito, nas ciências sociais de maneira geral. Sobretudo os últimos avanços da genética demonstraram que existe mais distância entre dois indivíduos de um chamado grupo racial do que entre dois grupos raciais de um mesmo ponto de vista genético. Desestrutura-se um pouco a noção tipológica e essencialista de raça que existiu no século XIX, não obstante essa noção perdure de certa forma na construção social que se produziu a respeito.

Aqui há dois problemas. Às vezes, quando se fala que um fenômeno é uma construção social, tende-se a subestimar a questão, como se fosse um problema de segunda ordem; quer dizer, tende-se a tratá-lo como um fenômeno de ordem subjetiva que, enquanto tal, não tem valor estruturante nem estrutural. Certa tradição no estudo da raça abordou mais esse ponto; creio que desde Max Weber já se vinha falando que a raça tem significação subjetiva, vem sendo interiorizada pelas pessoas, pelas sociedades. No entanto, eu diria que o lado mais frágil da noção de raça está no que se diz ser uma construção, e que, às vezes, ignora que na sociedade não há nada mais objetivo que a subjetividade. Por isso, mais do que falar em uma construção, em um problema subjetivo, sugiro que essa seja a outra objetividade, a objetividade da sociedade: o ser humano. Em sociedade nada acontece que não passe pela subjetividade dos seres humanos.

E com a construção da raça ocorre o mesmo; é uma construção social, mas, como tal, tem valores estruturantes, ou seja, define grupos e condiciona posições. Por ser uma construção social também está muito marcada pelos contextos, que têm vários momentos. O contexto tem a ver com certos canais de comunicação global, como o movimento das ideias foi sendo interiorizado, isto é, como passou a operar no interior das sociedades concretas, e como estas fizeram leituras desse "texto" global; nesse momento, então, entram em jogo as histórias particulares - que podem ser nacionais, regionais, locais e até familiares do fenômeno em questão.

Isso nos leva, portanto, a indagar que tipo de construção social, afinal, há em Cuba. O comentário a seguir é feito num registro sociológico, antropológico. Uma das primeiras perguntas que fizemos nas pesquisas sobre raça ${ }^{3}$ pedia que as pessoas a definissem. Foi feita a análise de mais de 500 discursos, decompondo-os pelo predicado usado para definir a raça. Recorrendo à teoria das representações sociais, sem medo de me equivocar, diria que, em Cuba, a noção de raça mais generalizada se configura em torno da cor da pele. Esse seria o núcleo estruturante da noção de raça das pessoas.

Logicamente, na construção social da cor da pele integram-se outros elementos, fundamentalmente os aspectos físicos da pessoa: o nariz, o cabelo, os lábios, etc. Essa noção popular nos coloca o problema do significado social 
e cultural que essas características físicas têm para as pessoas ao longo dos diferentes momentos históricos.

Deixando brevemente esses elementos de lado, passemos ao campo da representação social. Há um núcleo de representações que traz consigo outras ideias vinculadas à noção de raça. Emergem aqui ideias muito diversas. E dá-se muita importância a duas delas porque fazem parte de uma ideologia que atravessou todo o corpo social em Cuba e que se manifesta fortemente na definição de raça que as pessoas apresentam: de acordo com uma, a mestiçagem - aqui em Cuba, diz-se com frequência que "o que não tem de Congo tem de Carabalí"4 - aparece muito vinculada ao próprio conceito de raça, mas só quando as pessoas estão se referindo a esse conceito geral. E a outra é a noção de que todos somos iguais, de que não existem raças. É interessante como tal ideia está popularizada e deriva, às vezes, de uma ideologia política ou de uma cons trução científica de raça. Digamos que a resistência de uma raça é parte de uma polêmica que ainda existe atualmente. Se você vai à Europa e utiliza o termo raça, é visto como um indivíduo excêntrico; no entanto, nos Estados Unidos é normal conversar sobre a raça. Então, é essa mesma polêmica que se coloca no âmbito popular e que também tem raízes no pensamento cubano. Vemos um fiel exemplo na figura de [José] Martí, que, para realizar o projeto de independência da nação cubana que propôs, teve de fazê-lo com todos os fatores sociais. Daí vem a ideia da República "com todos, e para o bem de todos". E essa República não podia excluir os negros, porque, afinal, eles foram atores importantes da Guerra pela Independência. Dessa tradição vem essa noção que está nas representações das pessoas.

Junto a isso aparecem também nesses discursos outras ideias que já vinculam a raça a comportamentos culturais, estereótipos e problemas de origem que formam o núcleo em que se escondem os elementos da ideologia racista que sempre existiu em Cuba. Ou seja, é onde a noção de raça e aqueles traços fenotípicos adquirem conotações culturais concretas, que podem se converter em verdadeiros estigmas para determinados grupos raciais. Penso que esse é o elemento conceitual que opera em Cuba.

A genealogia é uma forma de estudar o fenômeno na Ilha; a que foi trabalhada em nossa pesquisa ${ }^{5}$ e que eu gostaria de destacar. A genealogia pode funcionar em estudos micro porque se fala em recordações; porém, para definir raça de um ponto de vista de pesquisas macro, ela tem seus inconvenientes. Mas devemos lembrar que se trata de uma prática que vem da influência da antropologia norte-americana e da concepção de raça nos Estados Unidos, muito associada à noção da gota de sangue. E para determinar a gota de sangue é necessário ir para a genealogia. No entanto, esses estudos esquecem que a memória genealógica nas classes populares não é muito forte e tende a se perder na segunda ou terceira geração ascendente. Em muitos casos, recorda-se do avô, mas se esquece do bisavô, de quem, o que fica, às vezes, é uma lenda. 
Hoje em dia, em nosso país, talvez as pessoas jovens conheçam mais seus bisavós porque a expectativa de vida é maior. Resumindo, ao andar pelo círculo da pesquisa, nos damos conta de que o importante é ir a esse sistema de representação que as pessoas têm do que são as raças.

Isso, porém, apresenta uma área de ambiguidade. Os modos como se conceitua regionalmente a raça, as suas formas de percepção, variam: uma pessoa que no ocidente do arquipélago é definida como mestiço, na região oriental, onde se matiza um pouco a cor da pele, pode passar como branco - é o que em Cuba se chama de branco oriental. Por outro lado, diante dessa ambiguidade, nós fizemos vários testes visando estabelecer um controle de como as pessoas definem a si mesmas e as outras. Quando cruzamos essa informação, nos demos conta de que em mais de $80 \%$ dos casos a autodefinição das pessoas coincide com a definição que os outros fazem dela. Esse dado contribuiu para mostrar que o núcleo das representações coincide com a real localização das pessoas nos grupos. Há cerca de I $5 \%$ de pessoas que se movem alternativamente dentro de um grupo e outro. É onde funcionam, talvez, as noções de origem e de contexto que lhes permitem mover-se de um grupo a outro, sobretudo os mulatos e os mestiços. Aí podem ocorrer autodefinições raciais muito contextuais de modo que definir-se como branco ou negro em determinada circunstância pode ser vantajoso; ou dois indivíduos com o mesmo fenótipo podem participar de um contexto distinto e fazer autodefinições diferentes, mas tudo isso é parte da complexidade de um problema como esse.

Y.S.H. Como o senhor entende a discriminação racial?

P.R.R. A discriminação racial não é mais do que a expressão instrumental, material, do racismo. Ou seja, ela ocorre quando grupos que ocupam posições de poder estabelecem limites ao desenvolvimento ou à possibilidade de integração de outros grupos. O aspecto instrumental do racismo se dá, sobretudo, quando ele tem expressões concretas de um ponto de vista estrutural. Constantemente os seres humanos estamos discriminando; é até mesmo uma questão gnoseológica, a apreensão de um conceito geral, em seus aspectos essenciais, implica a exclusão de toda uma série de características do indivíduo.

Em termos concretos a discriminação consiste nos limites sociais impostos a grupos de seres humanos em posição subordinada e tem expressão em diferentes esferas da vida social: na política; na economia; no acesso a bens universais; na cultura (há discriminação quando um modelo hegemônico impede o desenvolvimento de outras práticas culturais e tende a excluí-las); e também na educação. Também há quem veja discriminação por trás das relações íntimas e pessoais, como, por exemplo, quando as relações matrimoniais respondem a determinados tipos. Sempre se diz que uma sociedade alcançou seu ápice na igualdade racial quando não existem mais preconceitos nem limitações na relação de casais interraciais, ou quando as pessoas veem positiva ou natu- 
ralmente a formação de casais interraciais, porque, na minha opinião, essa é a esfera última em que se expressam os elementos discriminatórios.

A discriminação pode se dar de forma intencionada, estrutural, quando operam modelos de dominação configurados, ou pode ser produto das dinâmicas sociológicas concretas de grupos já socialmente "rotulados", que começam a reproduzir os mesmos elementos de exclusão.

Y.S.H. Podemos falar da existência de um racismo em Cuba? Como defini-lo? P.R.R. Como não?! O racismo é uma ideologia universal. O problema não é se podemos ou não falar de sua existência, mas as características que ele adota em Cuba, em cada contexto. O racismo é uma ideologia total, entendida a noção de ideologia como sistema de conhecimento historicizado e sistematizado que trata de explicar e organizar o mundo no nível teórico. No plano da psicologia social, opera em torno das dinâmicas dos preconceitos - como se produzem etc. - e se manifesta, além do mais, no aspecto institucional ou instrumental por meio da discriminação racial, que é um dos elementos que o compõem. É um fato que inclui práticas e ideologias, práticas e subjetividades que operam em toda a sociedade.

Pode-se dizer que em Cuba existe um modelo de racismo que foi sendo configurado historicamente e que, além disso, na própria Revolução foi-se convertendo cada vez mais no que chamo de um "racismo do porém", porque as pessoas dizem: "Eu não sou racista, porém..." A Revolução nasceu com um discurso igualitário, que condenava o racismo e que se impôs como modelo dominante. Simplesmente, estigmatizou-se o racismo e o racista, mas isso não resultou na sua eliminação. O racismo se escondeu, buscou seus espaços e suas maneiras de se expressar. Então, uma de suas expressões - ideológicas, digamos - é o "racismo do porém"; as pessoas não se reconhecem como racistas, mas exprimem uma série de preconceitos que se funcionalizam e geram espaços de desigualdade racial. Configura-se, portanto, uma dinâmica social que permite a criação de novas formas e a refuncionalização de desigualdades raciais de caráter histórico, não superadas.

Y.S.H. O senhor considera que há manifestações de racismo na juventude cubana? P.R.R. Cada um a sua maneira, todos temos. A juventude é um grupo social que vai sempre conectar elementos novos, mas trazendo os mesmos problemas das estruturas sociais. Isso, sim, tem particularidades! Uma das variáveis que nós colocamos em jogo foi a dos tempos. Da pesquisa sobre raça eu retirei a noção de que os tempos na sociedade não são "um tempo", mas dois, e que esses tempos se sobrepõem; eles têm a ver com a experiência vivida pelo grupo geracional, pelo grupo etário.

O resultado desse estudo apontou que as pessoas percebem que existem desigualdades raciais em Cuba atualmente. O grupo que revelava a mais alta 
percepção da reprodução dessas desigualdades raciais em todos os matizes de cor da pele era o grupo compreendido entre os 36 e os 60 anos. Ou seja, o grupo intermediário. Ao tomar a história particular desse grupo, nos damos conta de que ele é formado pelas pessoas que entraram na Revolução ainda crianças ou adolescentes e que assumiram, enquanto geração, o discurso da utopia de igualdade para todos; e para esse grupo os fenômenos novos então produzidos pareciam muito ofensivos. No entanto, no grupo de mais de 60 anos, que trazia a experiência anterior à Revolução, o nível de percepção das desigualdades raciais era muito baixo, praticamente inexistente. E no grupo dos jovens constatou-se que era também muito baixo, porque eles simplesmente se adaptaram e nasceram dentro do próprio processo de institucionalização da Revolução, no qual muitos aspectos estavam estabelecidos. Além disso, devemos ter presente que alguns desses jovens se formaram no processo do Período Especial ${ }^{6}$ e muitas dessas desigualdades eram naturais para eles.

Creio que a juventude assume as pautas de sua época, de seu contexto. É contraditório, porque, por outro lado, há mais casais interraciais entre os jovens do que entre os velhos. É uma dinâmica complexa, e eu não me atreveria a tentar esgotar todos os elementos; depende de onde o jovem está situado, do contexto, de sua história, de sua relação. Minha pesquisa indicou que, onde predominavam as relações de cooperação sobre a ação individual em todo o processo laboral, diminuíam os preconceitos raciais, que estavam mais próximos da fronteira em que se enfatizavam a atividade competitiva e a atividade individual. Então, avaliamos que isso vai sempre depender de um conjunto de circunstâncias que se vão desenvolvendo em uma dinâmica social.

Y.S.H. Quais desafios enfrentamos hoje em matéria de políticas sociais sobre a questão racial? Poderia se aprofundar sobre os ganhos e fragilidades a respeito desse tema, relacionando-o a outros países da região?

P.R.R. A Revolução entrou com uma política a respeito da mulher que mostrou avanço no que diz respeito a seu acesso universal. Avançou-se muito! No entanto, o tema racial, depois da década de I96o, ficou oculto, o que implicou falhas na política racial, deixando marcas. Sempre digo que há duas razões: uma é a doutrina; discutiase a hipótese de que solucionando o problema da classe, automaticamente solucionaríamos também o problema da raça. Nesse sentido, converteu-se em crença generalizada o fato de que em Cuba o problema racial havia sido resolvido na década de 1960 com todas as medidas de caráter popular adotadas pelo sistema revolucionário, que realmente identificou o negro; não se podem negar os avanços que teve a população negra, nesse sentido, nem tampouco que tivemos avanço.

A outra razão tem a ver com as próprias dinâmicas da Revolução. O tema racial foi concebido como capaz de gerar divisões internas em um país que estava vivendo um processo revolucionário muito intenso. Depois, vieram a crise econômica dos anos I990 e a reforma econômica, revelaram-se espaços 
competitivos, e as grandes diferenças entre os setores que ganhavam em divisas e o setor tradicional. Em todo esse processo se recoloca, se ressignifica a raça com todas as suas conotações, gerando desigualdade racial concreta, e o negro começa a encontrar barreiras na mobilidade de setores nesse período.

$\mathrm{Na}$ minha opinião, há certo atraso para reparar políticas sociais. Nesse sentido, posso dizer primeiramente que considero ter havido durante muito tempo carência de uma política social, acompanhada de certo atraso no estudo acadêmico do problema racial, o que gera grande perigo. Esse é um desafio. Há um processo de tomada de consciência no âmbito do poder, e a questão é como estruturar uma política social que tenda a resolver o problema racial e que não conduza necessariamente à marginalidade de um grupo.

O outro grande desafio em política social - também demasiadamente complexo - tem a ver com a passagem de um sistema social altamente centralizado a outro de maior descentralização. O que isso tem a ver com a raça? Refiro-me ao fato de que nossas políticas sociais são todas de corte universalista (educação, saúde) e obtiveram grandes conquistas no nível social, constituindo uma referência para a região. No entanto, o indivíduo cubano da década de i990 é diferente do dos anos I950, não há, por exemplo, analfabetismo, fome. Creio que as políticas adotadas depois do triunfo revolucionário alcançaram toda a população. No entanto, por trás da política social tem de haver um reconhecimento das especificidades de cada grupo sem marcar um em relação ao outro. Nesse sentido, existe um grupo intelectual, de afrodescendentes, que vai atrás da memória histórica. Em coerência, afirmo que para chegar a essa política social é preciso fazer uma história social para compreender o problema. Agora, os desafios estão sendo enfrentados como no processo de Revolução, isto é, a partir da prática. Neste momento existe no país a Comissão Aponte da Unión de Escritores y Artistas de Cuba (Uneac), uma comissão da Biblioteca Nacional que realiza propostas de políticas, e outras ações variadas estão sendo desenvolvidas. ${ }^{7}$

A outra grande limitação que a política social enfrenta é a falta de recursos. Insisto que esse é o nosso grande desafio, da indústria, da produção, enfim, de toda a sociedade cubana. Aí radicam os desafios da política social.

Y.S.H. Há alguns anos, em uma mesa para a qual foi convidado, o senhor sugeriu o seguinte: "[...] a segregação inscreve o racismo em um espaço e marca a organização geopolítica de um país ou sociedade [...]”. Suas palavras continuam valendo na atualidade? Nesse caso, como se manifesta tal evidência?

P.R.R. Naquela ocasião eu alertava para um problema que se podia produzir, olhando principalmente a experiência de outros contextos, um problema dessa população negra que vive em outras cidades e que, de maneira geral, formam núcleos conflituosos. Quando eu sugeri isso estava muito influenciado pela pesquisa que realizei, intitulada "Los marginales de las Alturas del Mirador", 
que investigava uma comunidade onde as pessoas viviam isoladas dos canais formais de comunicação porque, por exemplo, os matrimônios entre as pessoas dessa comunidade e do resto da cidade eram inexistentes. Estavam simples mente "rotulados" como palestinos, ilegais, gente de bairro marginal, o que gerava um nicho de reprodução dentro da própria população. A esses rótulos se agrega o fato de que a população desse bairro era predominantemente negra, mestiça - tratava-se assim de um gueto negro. Dessa maneira, pude ver o sentido sociológico desse fenômeno, raro em Cuba, e quis refletir sobre outros fenômenos sociais que se estavam produzindo naquele momento.

Y.S.H. Quais são as expressões de racismo na sociedade cubana hoje? Existem espaços que acentuam essas expressões?

P.R.R. Há um matiz diferenciador entre um setor da sociedade cubana atual, bastante amplo, que considera normais as relações interraciais de casal e outro que tem uma visão estereotipada dessas relações. Trata-se de ver, por meio de estudos, o que há de implícito nesses estereótipos. O problema da ideologia do racismo é que o racismo toma a experiência cotidiana de um ponto de vista cognitivo e a generaliza em forma de conceitos e representações que devolve à cotidianidade. Constantemente se reforça a cotidianidade, e isso gera um círculo vicioso de reprodução do racismo.

Em Cuba se pode falar de um racismo estigmatizado, que demonstra capacidade de sobreviver no tempo e reaparecer em condições propícias. Segundo a minha experiência, essa é uma contribuição que as pesquisas sobre as relações raciais podem oferecer. Por isso, insisto muito com jovens pesquisadores para que, quando forem trabalhar com esse tema, investiguem a década de I960 a fim de encontrar códigos e entender o que está sucedendo hoje em dia, bem como traçar conclusões que transcendam o registro descritivo.

No plano social, uma das expressões concretas do racismo ocorre nas áreas de desigualdade que foram sendo criadas. Isso se inter-relaciona com o que denominamos "a refuncionalização do preconceito". Tendemos a pensar que o preconceito é apenas uma questão subjetiva, mas ele é também estrutural, porque a posição de poder que tenha o indivíduo coloca sempre à frente os preconceitos que ele possui. Isso pode ser visto concretamente nas áreas de mobilidade (ascendente ou não), mas também em outras desigualdades, formando um circuito de fenômenos sociais interdependentes.

Y.S.H. Para finalizar, que fatores o senhor considera capazes de favorecer ou frear o desenvolvimento da população negra na sociedade cubana atual? P.R.R. Primeiramente, os históricos. Em segundo lugar, os fatores financeiros do espaço. O espaço é um lugar de expressão das desigualdades, e falar nas desigualdades raciais é falar em elementos que fortalecem o racismo. Como se soluciona isso? Primeiramente, acudindo políticas de ação afirmativa; quer 
dizer, identificando de forma pontual os nichos do problema e tomando medidas para solucioná-lo. Mas, sobretudo, gerando um pensamento realmente descolonizador. Isso exigiria uma leitura da história, uma reconceitualização de todos os instrumentos cognitivos mencionados. Essa batalha para acabar com as estruturas coloniais de nossas mentes e práticas é precisamente o meio pelo qual vamos de fato superar o problema do racismo. Eu resumiria isso em algumas palavras, com as quais sempre termino quando me entrevistam sobre o tema: o problema racial se resolverá quando se destruírem a negrura do negro e a brancura do branco.

Recebida em I7/08/20I6|Aprovada em 31/10/2016

Yeisa Sarduy Herrera é licenciada em sociologia com mestrado em desenvolvimento social pela Flacso - Cuba. É pesquisadora associada no Instituto Cubano de Pesquisa Cultural Juan Marinello e se dedica ao estudo das identidades na população jovem cubana em articulação com processos de desigualdades sociais. Conta com várias publicações tanto em revistas nacionais quanto estrangeiras. Tornou-se bolsista da Clacso em $2015 \mathrm{com}$ projeto intitulado A produção das desigualdades na América Latina e Caribe. 


\section{NOTAS}

I Pierson esteve no Brasil entre I935 e I937 para pesquisar a situação racial e cultural na Bahia, tema de seu doutoramento realizado na Universidade de Chicago sob orientação de Robert Ezra Park. Sua tese Negroes in Brazil, a study of race contact at Bahia, foi publicada em 1942 pela University of Chicago Press. [N. E.]

2 Esse texto foi vertido para o espanhol e para o inglês pelo autor nos anos I950 e I960. A revista de antropologia on-line Vibrant disponibilizou em 2008 as duas versões, indicadas nas referências biblilográficas. [N. E.]

3 Faz referência às pesquisas compiladas no texto Las relaciones raciales en Cuba, publicado pela Fundação Fernando Ortiz em 20 II.

4 No original, "el que no tiene de Congo tiene de Carabalí", em referência às etnias do antigo reino do Congo e do sul da Nigéria [N.T.].

5 Referência ao grupo de trabalho pertencente ao Instituto Cubano de Antropología (Ican), cuja investigação nessa temática foi essencial.

6 Referimo-nos à crise econômica que ocorreu desde os começos dos anos I990, após a perda de mais de $80 \%$ das fontes do comércio exterior - a União Soviética e o resto dos países do campo socialista - somada ao recrudescimento do bloqueio financeiro, econômico e comercial imposto pelo governo dos Estados Unidos a Cuba desde i96o. Essa crise causou notáveis impactos em todas as esferas da sociedade, e seus efeitos ainda se encontram vigentes. Nesse processo, levou-se a cabo a implementação de um conjunto de medidas que viabilizam um movimento de reestruturação denominado reforma.

7 O entrevistado faz referência a essas organizações; também há reconhecimento das diferentes pesquisas que foram realizadas no país sobre a questão racial. Nesse sentido, o antropólogo sugere que se perfilhem todos os estudos que historicamente se desenvolveram desde que existia o Instituto de Etnologia e Folclore até a atualidade: estudos sobre as religiões de origem africana, alguns realizados sobre os mercados e o trabalho nos portos marítimos. Na década de i980, esses estudos se erigiram como pesquisas de expressões culturais concretas da população de origem africana. De acordo com o entrevista- 
do, o ponto de inflexão dos estudos é marcado pelas pesquisas efetuadas por instituições pertencentes ao Citma, que colocaram a perspectiva de análise na questão das relações entre diferentes grupos raciais. Igualmente, reconhece a tarefa de estudiosos como Esteban Morales, Jesús Guanche, Tomás Robaina, Rodrigo Espina, Niurka Núñez, entre outros, que a partir de distintas vertentes se aproximaram da problemática.

\section{REFERÊNCIAS BIBLIOGRÁFICAS}

Carneiro, Edison (org.). (2005). Antologia do negro brasileiro. Rio de Janeiro: Agir, 2005.

Cavalcanti, Maria Laura Viveiros de Castro. (I996). Oracy Nogueira e a antropologia no Brasil: o estudo do estigma e do preconceito racial. Revista Brasileira de Ciências Sociais, I I/3 I, p. 5-28.

Costa Pinto, Luis de Aguiar. (I998). O negro no Rio de Janeiro. Relações de raças numa sociedade em mudança. Rio de Janeiro: Ed. UFRJ.

Fernandes, Florestan \& Bastide, Roger. (I959). Relações entre negros e brancos em São Paulo. São Paulo: Companhia Editora Nacional.

Freyre, Gilberto. (1977). Casa-grande \& senzala. Formação da família brasileira sob o regime da economia patriarcal. Rio de Janeiro: José Olympio.

Maio, Marcos Chor. (I999). O Projeto Unesco e a agenda das ciências sociais no Brasil dos anos 40 e 50. Revista Brasileira de Ciências Sociais, I4/4I, p. I4I-I58.

Myers, Jorge. (20I5). Uma Atlantic History avant la lettre. Transculturações atlânticas e caribenhas em Fernando Ortiz. Sociologia \& Antropologia, 5/3, p. 745-770.

Nogueira, Oracy. (2008a). Skin color and social class. Vibrant - Virtual Brazilian Anthropology, 5, I. Disponível em: <http:// www.vibrant.org.br/issues/v5n I/oracy-nogueira-skin-color-and-social-class/.> Acesso em 26 mar. 2017.

Nogueira, Oracy. (2008b). Color de piel y clase social. Vibrant - Virtual Brazilian Anthropology, 5, I. Disponível em: <http:// www.vibrant.org.br/issues/v5n I/oracy-nogueira-color-depiel-y-clase-social/>._Acesso em 26 mar. 2017. 
Nogueira, Oracy. (2007) Preconceito racial de marca e preconceito racial de origem: sugestão de um quadro de referência para a interpretação do material sobre relações raciais no Brasil. Tempo Social. Revista de Sociologia da USP, I9/I, p. 287-308.

Nogueira, Oracy. (1998). Preconceito de marca: as relações raciais em Itapetininga. Estabelecimento do texto, apresentação, organização e notas de Maria Laura Cavalcanti. São Paulo: Edusp.

Nogueira, Oracy. (1985). Tanto preto quanto branco: estudo das relações raciais. São Paulo: T.A. Queiroz.

Ramos, Guerreiro. (I954). O problema do negro na sociologia brasileira. Cadernos do Nosso Tempo, 2, jan.-jun., p. I89220.

Rodrigues, Nina. (2006). O animismo fetichista dos negros baianos. Apresentação e notas de Yvonne Maggie \& Peter Fry. Rio de Janeiro: Fundação Biblioteca Nacional/Ed. UFRJ.

Pierson, Donald. (I97I). Brancos e pretos na Bahia. São Paulo: Companhia Editora Nacional (Coleção Brasiliana, v. 24I). 


\section{“O PROBLEMA RACIAL SE RESOLVERÁ QUANDO SE DESTRUÍREM A NEGRURA DO NEGRO E A BRANCURA DO BRANCO". ENTREVISTA COM O ANTROPÓLOGO PABLO RODRÍGUEZ RUIZ}

Resumo

Nesta entrevista o antropólogo cubano Pablo Rodríguez Ruiz discute diferentes dimensões da questão racial no contexto cubano: a raça como construção social; as representações sociais existentes acerca dessa noção; a vigência histórica de uma ideologia do racismo em Cuba - que tem como uma das suas expressões o que denomina "racismo do porém". Abordam-se também as formas pretéritas e atuais do preconceito, da discriminação e das desigualdades raciais na sociedade cubana; e as conquistas, fragilidades e desafios das políticas públicas direcionadas à questão racial.

'THE RACIAL PROBLEM WILL BE SOLVED WHEN THE BLACKNESS OF THE BLACK AND THE WHITENESS OF THE WHITE ARE DESTROYED.' AN INTERVIEW WITH THE ANTHROPOLOGIST PABLO RODRÍGUEZ RUIZ

Abstract

In this interview, the Cuban anthropologist Pablo Rodríguez Ruiz discusses various dimensions of the racial question in the Cuban context: race as a social construct; the social representations surrounding this notion; and the historical existence of an ideology of racism in Cuba - one of the

\begin{abstract}
' of prejudice, discrimination and racial inequalities in $\mathrm{Cu}$ ban society; and the conquests, fragilities and challenges of public policies aimed at resolving racial issues.
\end{abstract}

Palavras-chave

Questão racial;

Cuba;

cor;

racismo;

Revolução Cubana.
Keywords

Racial question;

Cuba;

colour;

racism;

Cuban Revolution. 